The Journal of SPORT, 2014, 3(1), 30-62

(C) Kent State University

\title{
Understanding Online Purchase Intentions of Licensed Sport Merchandise through Integration of Technology Acceptance Model and Trust
}

\author{
Jinhee Yoo \\ University of Minnesota \\ Stephen D. Ross \\ University of Minnesota
}

\begin{abstract}
This study proposed and examined a research model to explain sport consumers' intentions to purchase licensed sport merchandise online. The model extends the TAM by adding the construct of trust in order to propose an adaptive model for the online sport context. The respondents were students $(\mathrm{N}=266)$ attending a large university in the Midwestern United States. The proposed model included measures of perceived ease of use, perceived usefulness, trust, attitude, and online purchase intentions of licensed sport merchandise. Structural equation modeling was used to test the proposed model and the relationships among constructs that were indicated by multiple measures. The results indicated that the proposed model $(\mathrm{x} 2 / \mathrm{df}=2.48, \mathrm{NFI}=.90, \mathrm{TLI}=$ .92 , CFI $=.94$, RMSEA $=.075$ ) fit the data with a degree of reasonable fit. The findings indicate a positive influence of perceived ease of use on perceived usefulness, perceived usefulness on attitude, and trust on attitude.
\end{abstract}


The Internet has provided sport businesses with more opportunities to increase revenues and reach more consumers. According to U.S. Census Bureau (2011), e-commerce of sporting goods accounts for $68.6 \%$ of total sales, $\$ 4.82$ million out of $\$ 7.03$ million in 2009 , up $19.2 \%$ compared to the previous year. In fact, ecommerce of sporting goods was the second largest increasing area followed by computer software in terms of change of sales volume. Furthermore, consumers now buy more sport products online than offline (U.S. Census Bureau, 2011), and as a result, major sectors of the sport industry including teams, leagues, and manufacturers also use the Internet as a critical component of their business strategy (Hur, Ko, \& Valacich, 2008). For example, the Minnesota Twins of the MLB sell tickets and merchandise, and also provide auction services through their website. As such, sport organizations now utilize the Internet as an outlet for information distribution, entertainment, a point of purchase for many consumers, while at the same time attempting to enhance interactive features and consumer satisfaction (Seo \& Green, 2008).

Due to the growth of e-commerce, researchers and practitioners have made efforts to understand the factors influencing online consumer behavior (e.g., Kim, Ferrin, \& Rao, 2008; Palvia, 2009; Zhang \& Won, 2009). Particularly, researchers have studied online consumer behavior by focusing on behavioral intentions (Kim et al., 2008; Pavlou \& Fygenson, 2006; Schlosser, White, \& Lloyd, 2006). In an effort to understand behavioral intentions in the ecommerce setting, the technology acceptance model (TAM) (Davis, 1986, 1989; Davis, Bagozzi, \& Warshaw, 1989), which was developed based on theory of reasoned action (Fishbein \& Ajzen, 1975), has been broadly used to explain how potential users accept or reject a technology (Davis et al., 1989).

The TAM has provided many researchers a conceptual framework for explaining online buying behavior (Gefen, Karahanna, \& Straub, 2003; Ha \& Stoel, 2009; Pavlou, 2003), and has been examined and proven to be robust and parsimonious in various contexts such as mobile commerce (Wu \& Wang, 2005), online learning (Saadé \& Bahli, 2005), online commerce and 
information systems (Bruner \& Kumar, 2005; Porter \& Donthu, 2006; Venkatesh \& Davis, 2000). Relative to this study, the TAM has been applied and extended in e-commerce contexts to understand the online consumer behavior due to the proliferation of e-commerce (Chiu, Chang, Cheng, \& Fang, 2009; Ha \& Stoel, 2009; Koufaris, 2002; Van der Heijden, Verhagen, \& Creemers, 2003).

Researchers have attempted to extend the TAM not only by testing the model in different contexts, but also finding additional constructs (Lin \& Lu, 2000). In particular, researchers have paid special attention to the construct of trust (Gefen et al., 2003; Van der Heijden, 2003; Van der Heijden et al., 2003). Researchers have argued that consumers may perceive more risk (e.g., fiduciary, security, and privacy risks) when shopping online than shopping in the traditional establishments because they need to depend on an unseen and unknown vendor (Everard \& Galletta, 2006). Therefore, many online customers still remain simply web site visitors, and not actual buyers. Because of this type of behavior, many online retailers are struggling to find a way to convert these visitors to actual customers (Donthu \& Garcia, 1999; Schlosser et al., 2006). As such, trust has been considered as a perceived risk reducer when shopping online (Van der Heijden et al., 2003). This issue highlights the importance of trust in online transactions because consumers hesitate to make a decision unless they trust the seller (Van der Heijden et al., 2003).

Given the increasing importance of the Internet as a platform of purchase for consumers (Seo \& Green, 2008), it is significant to understand how consumers make decisions to buy products online. Despite the proliferation of online consumer studies, little empirical research has been conducted to explain factors that influence purchasing intentions of licensed sport merchandise, especially in online settings. Previous research that tried to explain the online buying behavior in sports has specifically focused on intangible sport products such as sports-related information (Hur et al., 2008; Hur, Ko, \& Claussen, 2011; Seo \& Green, 2008). The models and factors used in the previous research may not be directly applied to explain online purchasing intentions of more tangible sport products. 
Sport products consist of tangible and intangible elements (Mullin, Hardy, \& Sutton, 2007). Vijayasarathy (2002) suggested that intentions to shop using the Internet are different between tangible and intangible products. Therefore, a conceptual model that explains online purchasing intention of tangible sport products is needed. This study focused on tangible sport products, specifically licensed sport merchandise.

The purpose of the present research is to propose and empirically test a conceptual model to explain how sport consumers intend to purchase licensed sport merchandise online. Specifically, this study extends the TAM to include trust to propose an adaptive model for the online sport context. This study will provide a more thorough understanding of consumer behaviors in the online environment for researchers and practitioners who are interested in factors that influence online purchase intention of sport product. In addition, the application of such a model to a variety of online sports consumptions in future contexts may contribute to the advancement of a body of knowledge in the field of sport marketing.

\section{Theoretical Background}

\section{Technology Acceptance Model (TAM)}

Davis $(1986,1989)$ introduced the TAM as an adaptation of theory of reasoned action (TRA: Fishbein \& Ajzen, 1975) model to explain why a particular system may be acceptable to users. TRA has been broadly used to predict behavioral intentions and/or behavior (Madden, Ellen, \& Ajzen, 1992; Hansen, Jensen, Solgaard, 2004). According to TRA, a single behavior is determined by the intentions to perform the specific behavior (Ajzen \& Fishbein, 1977, 1980), and behavioral intentions are a function of subjective norm and attitude toward the behavior (Fishbein \& Ajzen, 1975; Hansen et al., 2004).

In the TAM, subjective norm which was originally included in TRA was eliminated because it is the least understood facet of TRA for buying behavior based on technology (Davis et al., 1989). The TAM has been broadly tested in various technology-related contexts (Ha \& Stoel, 2009; Porter \& Donthu, 2006) including the 
workplace (Davis, Bagozzi, \& Warshaw, 1992; Igbaria, Iivari, \& Maragahh, 1995; Venkatesh \& Bala, 2008), the Internet or website use (Brunner \& Kumar, 2005; Moon \& Kim, 2001), and online shopping settings (Gefen et al., 2003; Koufaris, 2003; Palvia, 2009; Pavlou, 2003).

The TAM specifies the relationship between perceived usefulness, perceived ease of use, users' attitude, intentions, and actual computer adoption behavior (Davis et al., 1989). More specifically, a person's computer usage is determined by behavioral intentions. Subsequently, behavioral intentions are determined by the person's attitudes toward using the system and perceived usefulness. The attitudes are influenced by two internal beliefs, such as perceived usefulness and perceived ease of use, which are mainly relevant to computer acceptance behaviors. Perceived ease of use has a causal effect on perceived usefulness (Davis, 1993; Davis et al., 1989). Further, perceived usefulness and perceived ease of use mediate the effects of external variables including system characteristics, development processes, and training on behavioral intentions (Davis, 1993; Davis et al., 1989; Venkatesh \& Davis, 2000). Perceived usefulness and perceived ease of use are the key antecedents of the TAM constructs (Venkatesh, 2000). The TAM is presented in Figure 1.

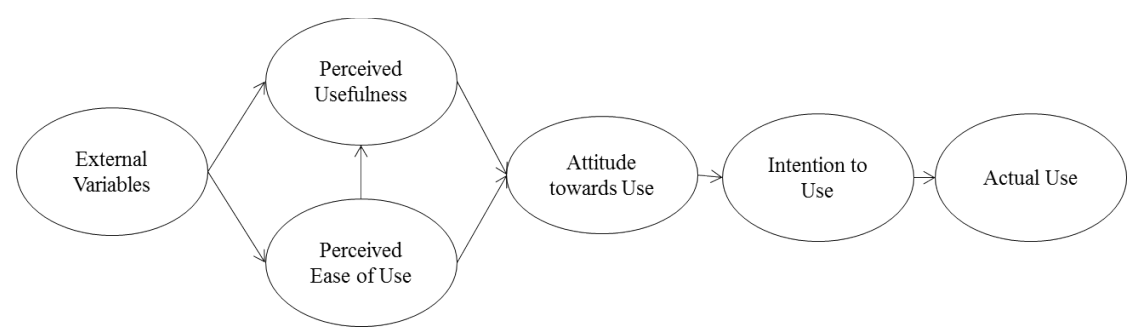

Figure 1.The Technology Acceptance Model (Davis, 1986, 1989; Davis et al., 1989)

As Davis (1989) stated, "perceived usefulness is the degree to which a person believes that using a particular system would enhance his or her job performance" (p. 320). Perceived usefulness was derived from expectancy theory (Porter \& Lawler, 1968) which 
suggests a person continuously evaluates the consequences of his/her behavior and assesses the likelihood that the action will produce various results in a subject way. Perceived usefulness should be fully considered when designing or implementing successful systems because user's technology acceptance is strongly influenced by perceived usefulness. How users perceive risks in using and adopting the technology can have different effects on the influence of perceived usefulness. For example, if users perceive that the risk of technology is low, perceived usefulness should be emphasized.

Perceived ease of use is "the extent to which a person believes that using a particular system would be free of effort" (Davis, 1989, p. 320). Self-efficacy theory (Bandura, 1982) can be seen as similar to perceived ease of use, as it refers to "judgments of how well one can execute courses of action required to deal with prospective situations" (Bandura, 1982, p. 122). The TAM suggests that perceived ease of use is instrumental in explaining the variance in perceived usefulness (Ha \& Stoel, 2008). For example, if an online consumer believes a website is easy to use, he or she will tend to perceive the website as being useful. Therefore, online consumers do not have to waste time by understanding how to use the systems, and spend more time to search for information about the product they want to buy. Individual's behavioral intentions to use an information technology is determined by perceived usefulness and perceived ease of use in the TAM.

\section{Trust}

Trust is a set of specific beliefs including integrity, benevolence, ability, and predictability (Gefen et al., 2003). Integrity refers to a set of principles provided by the trustee found to be acceptable by the trustor (Mayer, Davis, \& Schoorman, 1995), while benevolence is "based on the extent to which the retailer believes that the vendor has intentions and motives beneficial to the retailer when new conditions arise, conditions for which a commitment was not made" (Ganesan, 1994, p. 3). Ability describes how a trustee has functional competence, interpersonal competence, business sense, and judgment (Gabarro, 1978; Mayer et al., 1995). Finally, 
predictability evaluates if consumers can predict or expect the vendor will behave with reliability in order to reduce social uncertainty (Gefen \& Straub, 2004).

Researchers have emphasized the importance of trust by stating that although the use and popularity of online transactions have grown, the inherent uncertainty in the online consumption environment brings the issue of trust towards the Internet as a transactional means to the forefront of academic and practical marketing research (Ha, 2003; Kim et al., 2008; Pavlou, 2003). Unlike traditional transactions, online purchases have a higher possibility of significant fiduciary, security, and privacy risk due to lack of vendors' visibility (Everard \& Galletta, 2006). These possible risks, therefore, make trust a critical component in online transactions given the reduction in perceived risk among consumers (Pavlou, 2003). Many researchers have also suggested that the development and maintenance of consumer brand trust on the web should be at the core of companies' marketing plans (Fournier \& Yao, 1997; Ha, 2003).

However, Gefen (2004) pointed out that it is costly for companies to invest in systems for ensuring trust in the short run, given that relationships based on trust are likely to be long term and result in higher levels of loyalty and reduced costs for negotiation, monitoring, and transaction. Given that trust is considered to be a short-term issue and also the most critical long-term obstacle for the consumers (Kim, Kim, \& Shin, 2009), trust has been integrated into the TAM. As a result, both the technology-oriented and the trustoriented viewpoints jointly became mainstream in explaining the online consumer behavior (Van der Heijden et al., 2003). That is, researchers have strived to explain the online consumer behavior by incorporating the technology-oriented and the trust-oriented viewpoints (Van der Heijden et al., 2003). Gefen et al. (2003) proposed a model based on the TAM by adding trust and its antecedents (e.g., knowledge-based trust, institution-based trust, and calculative-based trust). Trust was included as an antecedent of online purchase intention. Kim, Kim, and Shin (2009) applied the TAM in the e-commerce settings (i.e., the airline B2C e-commerce 
websites), and suggested that trust is one of the most important longterm barriers for online shopping for both consumers and firms.

In a sport context, it has been found that trust also is an important factor that significantly influences the online purchasing intention. Zhang and Won (2009) suggested that sport consumers should accept the e-commerce first when purchasing sport product, and trust plays the most important role as a determinant of online purchase intention.

\section{Research Model and Relationship Hypotheses}

The model proposed here is derived primarily from an integrated model for trust and the TAM in online shopping by Gefen et al. (2003), yet was applied to the sport context. The final integrated model consists of five constructs including perceived ease of use, perceived usefulness, trust, attitude, and online purchase intentions. The model proposes the influence of perceived ease of use on perceived usefulness, attitude, and online purchase intentions; the influence of perceived usefulness on attitude and online purchase intentions; the influence of trust on attitude and online purchase intentions; the influence of attitude on online purchase intentions. The research model is presented in Figure 2. Following research propositions are suggested based on the literature reviewed.

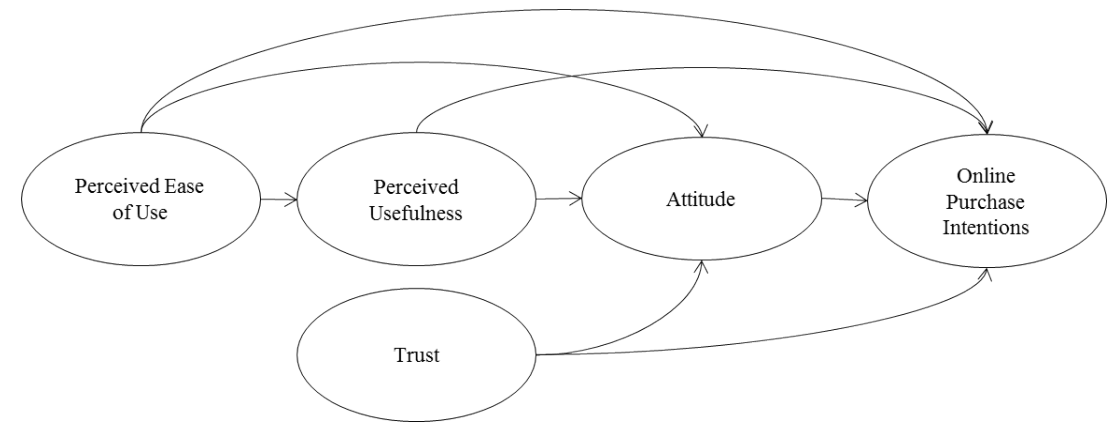

Figure 2. A Research Model for Online Purchase Intentions of Licensed Sport Merchandise 


\section{Perceived Ease of Use and Perceived Usefulness}

According to the TAM, there is a positive relationship between perceived usefulness and perceived ease of use (Van der Heijden, 2003). Specifically, perceived usefulness is influenced by perceived ease of use (Ha \& Stoel, 2009; Saadé \& Bahli, 2005), given that the system is developed and enhanced by making it easier to use (Venkatesh \& Davis, 2000). This suggests that if a sport consumer believes that the website selling the sport product is easy to learn or use, he or she will tend to consider these systems as more useful compared to their competitors (Bruner \& Kumar, 2005; Wu \& Wang, 2005). This process therefore helps the consumer to have an intention to buy the sport product in the website. As such the following hypothesis is offered:

Hypothesis 1: A sport consumer's perceived ease of use of a website for licensed sport merchandise will significantly influence perceived usefulness of the website.

\section{Perceived Ease of Use and Attitude}

Like perceived usefulness, perceived ease of use is also a belief that influences consumer's attitude toward the technology (Davis et al., 1989; Van der Heijden, 2003; Porter \& Donthu, 2006). When sport consumers believe that a website is easy to use, learn, or navigate, they are more likely to have positive attitude toward using the website. Although both perceived usefulness and perceived ease of use have positive effects on attitude, the effect of ease of use on attitude is debated (Ha \& Stoel, 2009). For example, compared to perceived usefulness, perceived ease of use has a weaker direct effect on attitude (Davis, 1989; Porter \& Donthu, 2006). On the other hand, Van der Heijden (2003) suggested that perceived ease of use influences attitude at almost the same level as perceived usefulness. Therefore, an effect of perceived ease of use on attitude should be examined in order to understand the relationship between perceived ease of use and attitude. Therefore, it is posited that:

Hypothesis 2: A sport consumer's perceived ease of use of a website for licensed sport merchandise will significantly 
influence attitude toward buying licensed sport merchandise in the website.

\section{Perceived Ease of Use and Online Purchase Intentions}

In online consumer behavior, a web interface that is perceived as easy to operate tends to be more accepted by consumers (Pavlou, 2003). Many researchers found that perceived ease of use has a direct effect on various behavioral intentions such as intentions to return to an e-vendor, intentions to use the communication technology, intentions to transact online, and intentions to use the information technology (Gefen et al., 2003; Im, Kim, \& Han, 2008; Pavlou, 2003; Venkatesh, 2000; Venkatesh \& Davis, 2000). In the sport context, Hur (2007) found that a sports fan's perceived ease of use of a sports website positively influences intentions to use the website. Therefore, it is posited that:

Hypothesis 3: A sport consumer's perceived ease of use of a website for licensed sport merchandise will significantly influence the intentions to buy licensed sport merchandise online.

\section{Perceived Usefulness and Attitude}

Lin and $\mathrm{Lu}$ (2000) referred to a preference for a website as an attitude and suggested that perceived usefulness positively influences a preference for a website. How useful a website is an important factor for consumers when developing an attitude toward using the website (Davis et al., 1989; Porter \& Donthu, 2006). Many researchers have found that attitude mediates perceived usefulness and behavioral intention. For example, Davis et al. (1989) and Van der Heijden (2003) found that attitude is a mediator between perceived usefulness and behavioral intention. That is, if sport consumers believe that the website is useful, they will have a positive attitude toward the website, and then they have intentions to buy sport products from the website. This leads to the following hypothesis posited:

Hypothesis 4: A sport consumer's perception of usefulness of a website for licensed sport merchandise will significantly 
influence attitude toward buying licensed sport merchandise from the website.

\section{Perceived Usefulness and Online Purchase Intentions}

Perceived usefulness has been shown as a strong determinant of usage intentions in both with-attitude and without-attitude models (Venkatesh \& Davis, 2000). Venkatesh and Bala (2008) found that perceived usefulness is the strongest predictor of behavioral intention among perceived ease of use, subjective norm, experience, and voluntariness. In the sport context, Hur, Ko, and Claussen (2011) suggested that a sports fan's perception of the usefulness of a sports website will positively influence intention to use the website. This leads the following hypothesis to be proposed:

Hypothesis 5: A sport consumer's perception of usefulness of a website for licensed sport merchandise will significantly influence the intentions to buy licensed sport merchandise online.

\section{Trust and Attitude}

Website trust is highly correlated with satisfaction, and online consumer's satisfaction and/or dissatisfaction can be also viewed as attitude toward online consumption (Yoon, 2002). Therefore, trust toward the web vendor has a positive influence on attitude for the website vendor (Ha \& Stoel, 2009; Palvia, 2009). Teo and Liu (2007) examined the antecedents and consequences of consumer trust, and found that consumers' trust toward the e-vendor has a positive effect on attitude. Lim, Sia, Lee, and Benbasat (2006) also suggested an indirect relationship between trust and online purchase intention through attitude toward online shopping. Therefore, following hypothesis is suggested:

Hypothesis 6: A sport consumer's trust toward a website for licensed sport merchandise will significantly influence attitude toward buying licensed sport merchandise from the website. 


\section{Trust and Online Purchase Intentions}

Trust plays a critical role in consumer's adoption of online shopping (Ha \& Stoel, 2009), and Yoon (2002) found that web-site trust positively influences online purchase intention. Beliefs in integrity, competence, and benevolence of a website positively influence consumer's trust of the website (Palvia, 2009). In addition, the consumers who trust the website are more likely to transact online. There was a direct and indirect positive relationship between trust and online purchase intention (Lim, Sia, Lee, \& Benbasat, 2006; Pavlou, 2003). Jarvenpaa, Tractinsky, and Vitale (1999) found that trust influences the consumer's attitude and risk perceptions, and in turn it influences the willingness to buy online.

Further research by Bart, Shankar, Sultan, and Urban (2005) examined the relationships among website and personal characteristics, online trust, and behavioral intention. They found that online trust partially mediates the relationships between website characteristics and behavioral intent. They categorized the website characteristics such as privacy, security, navigation and presentation, brand strength, advice, order fulfillment, community features, and absence of errors. Specifically, privacy, navigation, advice, order fulfillment, and absence of errors were found to be important for building trust in e-tail websites. Additionally, this mediating effect was found to be strong for sites with infrequently purchased and high-involvement items, but weak for the websites with frequent transactions. Pavlou (2003) found that trust affects perceived risk, perceived usefulness, and perceived ease of use, and in turn, purchase intention. Given this extensive research, it is posited that:

Hypothesis 7: A sport consumer's trust toward website for licensed sport merchandise will significantly influence the intentions to buy licensed sport merchandise from the website.

\section{Attitude and Online Purchase Intentions}

Attitude toward online purchase is a critical variable to differentiate between sport product online buyers and sports website browsers (Zhang \& Won, 2010). Lim et al. (2006) suggested that 
attitude toward online shopping has a positive effect on willingness to buy online. In the original TAM, attitude was included as a mediator between perceived usefulness, perceived ease of use, and behavioral intentions. Many researchers (Bruner \& Kumar, 2005; Ha $\&$ Stoel, 2009; Lin \& Lu, 2000) have examined the mediating role of attitude in the process of online buying behavior. However, there is a lack of consensus regarding this mediating role of attitude (Davis et al., 1989; Gefen et al., 2003; Pavlou, 2003; Venkatesh, 2000; Venkatesh \& Davis, 2000), since it partially mediates perceived usefulness and behavioral intention (Venkatesh, 2000). That is, although perceived usefulness has a weak effect on attitude, perceived usefulness still has a strong effect on behavioral intentions (Venkatesh, 2000). However, Van der Heijden (2003) argued that attitude plays a powerful role as a mediator between beliefs and the intention to use. Therefore, it is suggested that attitude should be included in the proposed model, and the following hypothesis generated:

Hypothesis 8: A sport consumer's attitude toward buying licensed sport merchandise in the website will significantly influence the intentions to buy licensed sport merchandise from the website.

\section{Sample}

\section{Methodology}

College-aged consumers are likely to be familiar with the Internet and a major target market for online retailers (Ha \& Stoel, 2009) and for licensed sport merchandise (Kwon \& Trail, 2001; Zhang \& Won, 2009). Furthermore, a theoretical relationship between constructs may be sound if a homogeneous sample is used (Iwasaki \& Havitz, 1998). For these reasons, the college student market is considered to provide important information about the online purchase intentions of young adults.

As such, non-probability sampling was utilized through a convenience sampling method to recruit participants in the study. Respondents consisted of 538 graduate and undergraduate students who enrolled sport management and general kinesiology courses at a 
large Midwestern university in the U.S. Among the respondents, 266 who had experience in buying licensed sport merchandise online were selected as the final sample by asking a qualifying question on whether the respondent had previously purchased a licensed sport merchandise using the Internet or not. The focus on including theses respondents was due to the intent of the study and targeting only those with experiences purchasing licensed sport merchandise online, and the scales that were developed based on respondents' experiences.

\section{Procedure and Instrument}

The survey was reviewed and approved by the Institutional Review Board (IRB) on the campus before conducting survey. Upon approval from the IRB, a pilot study was conducted to establish content validity by assessing the perspective of participants to ensure that the instrument is comprehensible to the target sample (Andrew, Pedersen, \& McEvoy, 2011). A total of 42 undergraduate students in a sport management course participated in the pilot study. Respondents were not only asked to complete the survey, but also to provide feedback on item wording and phrasing that were needed to further revise the instrument. A panel of experts also provided suggestions regarding the organization of the online survey and phrasing of specific items to establish content and face validity of the instrument. After revising the instrument based on the pilot study and a panel of experts, instructors for undergraduate and graduate level courses were contacted in order for their students to be asked to participate in the survey. The survey was conducted in classrooms. Each participant was asked to participate in the survey only one time in order to avoid redundancy.

A self-administered questionnaire was used in the study, and scales for perceived usefulness, perceived ease of use, and trust were adapted from Gefen et al.'s (2003) study. Scales for attitude and online purchase intention were derived from Ajzen and Madden (1986) and Pavlou (2003), respectively. Perceived usefulness, perceived ease of use, trust, and online purchase intention are 7-point Likert type scale ranging from 1 (Strongly Disagree) to 7 (Strongly 
Agree). The measures of attitude were obtained by evaluative semantic differential scales ranging from +3 to -3 .

To evaluate the internal consistency of the variables, Cronbach's alpha coefficients were calculated. Reliability of the measures was confirmed as all the measures had the Cronbach's $\alpha$ coefficient above the acceptable level of .70 (Nunnally, 1978). Average variance extracted (AVE) values were calculated for each construct to ensure that each indicator represents the latent construct. All latent scale values were greater than the suggested cut-off value of .50 (Fornell \& Larcker, 1981; Hair, Anderson, Tatham, \& Black, 1998; Kwon \& Armstrong, 2006). Reliability of the scale is presented in Table 1.

Table 1.

Reliability of the Scales

\begin{tabular}{lccc}
\hline \multicolumn{1}{c}{ Construct } & Number of items & Cronbach's $\alpha$ & $A V E$ \\
\hline Perceived ease of use & 6 & .842 & .577 \\
Perceived usefulness & 6 & .851 & .662 \\
Trust & 7 & .827 & .626 \\
Attitude & 8 & .855 & .548 \\
Online purchase intentions & 3 & .834 & .639 \\
\hline
\end{tabular}

\section{Data Analysis}

SPSS 19.0 and AMOS 18.0 were used for data analysis. Prior to actual analysis, descriptive statistics were generated for each item and construct such as means, variance, median, and normality in order to screen the data by checking the qualifying question, outliers, missing, and unreliable data. After data cleaning, 266 out of 538 were valid for analysis. Correlation analysis was conducted to test for multicollinearity and convergent validity. Confirmatory factor analysis (CFA) was conducted to test the validity of the measurement model using AMOS 18.0. Next, structural equation modeling (SEM) was conducted to confirm the research model using AMOS 18.0, allowing the researchers to examine both the path structure of the latent model and the factor loadings of the 
measurement model. Furthermore, SEM allows researchers to test and explain measurement issues (Kwon \& Armstrong, 2006).

\section{Results}

Means, standardized deviations, skewness, and kurtosis values were calculated to determine normality of the data. Absolute skewness and kurtosis values for all constructs were no greater than 3.0 and 8.0, respectively, indicating the data was close to normal distribution (Kline, 2011). The correlation matrix indicated that significant levels of multicollinearity did not exist (Kline, 2011), and the correlations among the constructs ranged from .428 to .784 (see Table 2). Therefore, the data seemed to have no issues in multicollinearity and showed evidence of convergent validity.

Table 2.

Correlations between Constructs

\begin{tabular}{|c|c|c|c|c|c|}
\hline & $\begin{array}{c}\text { Perceived } \\
\text { ease of } \\
\text { use } \\
\end{array}$ & $\begin{array}{l}\text { Perceived } \\
\text { usefulness }\end{array}$ & Trust & Attitude & $\begin{array}{c}\text { Online } \\
\text { purchase } \\
\text { intentions }\end{array}$ \\
\hline $\begin{array}{l}\text { Perceived } \\
\text { ease of use }\end{array}$ & 1 & & & & \\
\hline $\begin{array}{l}\text { Perceived } \\
\text { usefulness }\end{array}$ & $.784^{* *}$ & 1 & & & \\
\hline Trust & $.770^{* *}$ & $.702^{* *}$ & 1 & & \\
\hline Attitude & $.428^{* *}$ & $.488^{* *}$ & $.488^{* *}$ & 1 & \\
\hline $\begin{array}{l}\text { Online } \\
\text { purchase } \\
\text { intentions }\end{array}$ & $.730^{* *}$ & $.725^{* *}$ & $.697^{* *}$ & $.447^{* *}$ & 1 \\
\hline$M$ & 5.681 & 5.450 & 5.640 & 5.834 & 5.607 \\
\hline$S D$ & .964 & 1.092 & 1.048 & .805 & 1.080 \\
\hline Skewness & -1.306 & -.927 & -.910 & -1.682 & -1.076 \\
\hline Kurtosis & 3.007 & 1.385 & .935 & 5.329 & 1.866 \\
\hline
\end{tabular}

The results of the revised measurement model revealed an adequate fit to the data $\left(x^{2} / d f=2.49<3.0, p=.001, \mathrm{NFI}=.90, \mathrm{TLI}=\right.$ $.91, \mathrm{CFI}=.94, \mathrm{RMSEA}=.075)$. The convergent validity of the 
model was examined by factor loadings for each manifest variable. As shown in Figure 3, all the factor loadings in the model were higher than .50 , indicating that each of the manifest variables had more common variance to explain its associated latent variable than error and/or unique variance (See Figure 3).

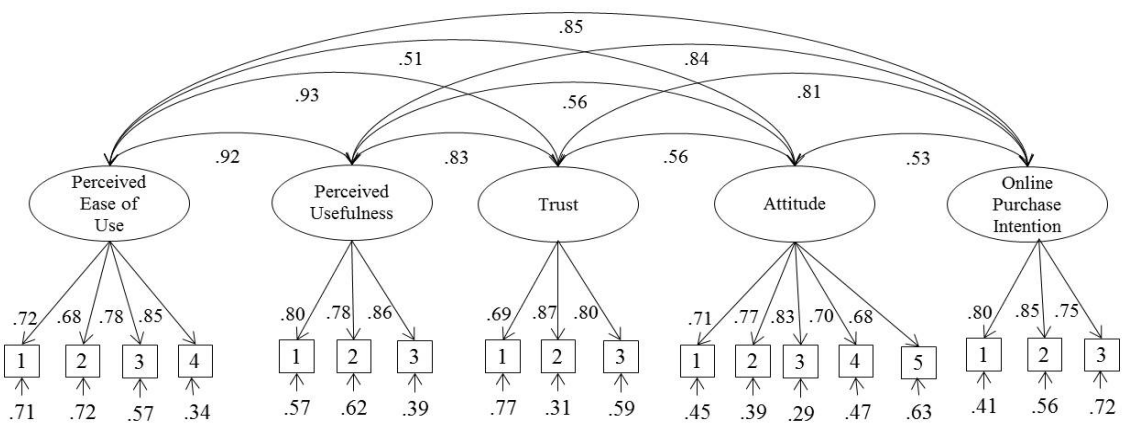

Figure 3.CFA Estimation Results

Based on the CFA results, SEM was conducted in order to examine the fit between the proposed model and the data. The results indicated an adequate fit to the data $\left(x^{2} / d f=2.48<3.0, p=.001\right.$, NFI $=.90, \mathrm{TLI}=.92 \mathrm{CFI}=.94$, RMSEA $=.075)$. Next, the hypotheses were examined by conducting path analysis for testing statistical significance for the path coefficients between constructs. Three hypotheses were supported and five were rejected. As shown in Figure 4 and Table 3 , the data supported a positive relationship between perceived ease of use and perceived usefulness (H1), perceived usefulness and attitude (H4), and trust and attitude (H6).

Specifically, perceived ease of use has a significant impact on perceived usefulness $(\beta=.91)$, explaining $82.8 \%$ of the variance. However, impacts of perceived ease of use on attitude $(\beta=-.65)$ and online purchase intentions $(\beta=.37)$ were insignificant. In terms of perceived usefulness to attitude, the coefficient was significant $(\beta=$ .60 ), explaining $36.5 \%$ of the variance while perceived usefulness to online purchase intentions $(\beta=.34)$ was insignificant. Link from trust to attitude $(\beta=.65)$ was significant, explaining $42.4 \%$ of the 
variance whereas trust to online purchase intentions $(\beta=.15)$ was not significant. Finally, the influence of attitude on online purchase intentions $(\beta=.07)$ was not significant.

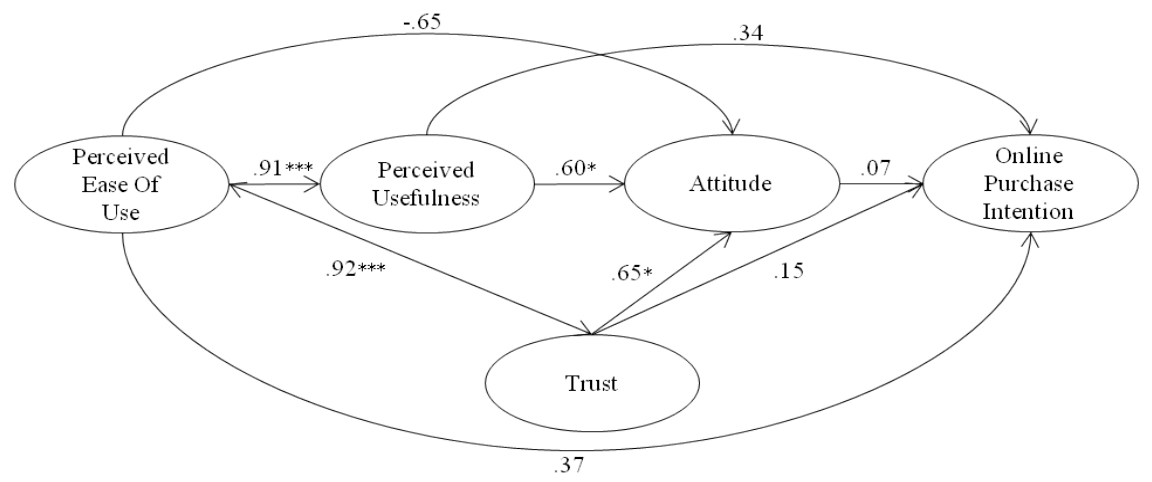

Figure 4. SEM Estimation Results

Table 3.

The Results of Hypothesis Tests

\begin{tabular}{lllll}
\hline Hypothesis & \multicolumn{1}{c}{ Path } & Estimate & $S E$ & C.R. \\
\hline H1 & $\begin{array}{l}\text { Perceived ease of use } \rightarrow \\
\text { Perceived usefulness } \\
\text { H2 }\end{array}$ & .91 & .09 & $11.41^{* * *}$ \\
Perceived ease of use $\rightarrow$ & -.65 & .32 & -1.55 \\
H3 & $\begin{array}{l}\text { Attitude } \\
\text { Perceived ease of use } \rightarrow \\
\text { Online purchase intentions } \\
\text { H4 }\end{array}$ & .37 & .37 & 1.15 \\
Perceived usefulness $\rightarrow$ & .60 & .17 & $2.44^{*}$ \\
H5 & $\begin{array}{l}\text { Attitude } \\
\text { Perceived usefulness } \rightarrow\end{array}$ & .34 & .19 & 1.75 \\
H6 & $\begin{array}{l}\text { Online purchase intentions } \\
\text { Trust } \rightarrow \text { Attitude }\end{array}$ & .65 & .23 & $2.22^{*}$ \\
Trust $\rightarrow$ Online purchase & .15 & .26 & .66 \\
H8 & $\begin{array}{l}\text { intentions } \\
\text { Attitude } \rightarrow \text { Online purchase } \\
\text { intentions }\end{array}$ & .07 & .10 & .98 \\
$* * * p<.001, * p<.05$ & & & & \\
& & & &
\end{tabular}




\section{Discussion}

Significance of the online stores has increased as a distribution channel for licensed sport merchandise. Along with the advances in e-commerce, sport consumers have shown different consumption patterns compared to past. Online sport consumers are likely to purchase licensed sports merchandise of a certain team or brand based on their volitional motivation (Deci, Koestner, \& Ryan, 1999). This implies that sport consumers are distinctive from other consumers. It also suggests a need for research to understand sport consumers' distinctiveness and uniqueness. Therefore, the purpose of this study was to test a proposed research model to account for intentions to purchase licensed sport merchandise online. Furthermore, the study attempted to gain a better understanding of the factors influencing online sports product purchasing behavior. The proposed model included perceived ease of use, perceived usefulness, trust, attitude, and online purchase intentions, and was proven that the model is suitable to explain intentions to buy sports product online.

\section{Influence of Perceived Ease of Use}

As expected, perceived usefulness increased as perceived ease of use increased. The results are consistent with previous findings that perceived ease of use is a strong predictor of perceived usefulness (Chiu et al., 2009; Kim et al., 2009; Palvia, 2009; Pavlou, 2003). The results imply that the more the sports fans perceive the online store to be easy to learn and provide flexible interaction, clear, and understandable, the more likely they will consider the online store as useful. Therefore, perceived ease of use can be considered as the basic component for a success of online sport product stores. In order to ensure the website is easy to use and ultimately successful, the efficiency of the site's navigation, sufficient information ( $\mathrm{Da}$ Silva \& Alwi, 2008), fast page downloading speed, consistent accessibility, and easy product order process should be considered (Rios \& Riquelme, 2010).

Given the relationships among the constructs, the results are partly supportive of other TAM studies. The findings suggested that 
there were no significant effect of perceived ease of use on attitude and online purchase intentions. The reason for the failure to detect significance may be that the respondents were students, who are most likely technologically savvy (Tsuji, Bennett, \& Leigh, 2009). That is, perceived ease of use may not contribute to a positive attitude and online purchase intentions once a certain evaluation level has been reached (Van der Heijden et al., 2003). Second, the results also reveal that the process to purchase product may be different depending on product, resulting from the level of involvement with the product. That is, if consumers are not highly involved with a product, they may not consider ease of use because they are more likely to make a decision fast and easy as compared to when they are highly involved.

\section{Influence of Perceived Usefulness}

The findings of this research suggest that perceived usefulness has a positive influence on attitude. This finding is consistent with previous studies, supporting that perceived usefulness is a major component of the TAM (Bruner \& Kumar, 2005; Childers, Carr, Peck, \& Carson, 2001; Davis, 1993; Ha \& Stoel, 2009). The results also suggest that the more consumers perceive the online store to help them search and buy merchandise effectively, the more likely they will have favorable and positive attitude toward using the online store.

However, perceived usefulness did not have a significant impact on online purchase intentions. According to Van der Heijden et al. (2003), the TAM model focuses on usage intentions of the technology rather than purchase intentions. Usage intentions may be broader in scope than purchase intentions in an online transaction context because an individual may use an online store not only to purchase, but also to learn about products and services. Therefore, people may not intend to buy sports merchandise at the online store, even though they perceive the online store as useful (Van der Heijden et al., 2003). Furthermore, perceived usefulness might not matter if the respondents of the study are loyal customers of the online stores they have used. For example, if a customer buys a 
sports merchandise from a certain online store frequently, the customer may use the website automatically without considering alternatives. The customer will know about how the website is organized and the ordering process is operated, thus, not need to consider how useful the website is prior to decision making.

\section{Influence of Trust}

In regards to trust, this study showed that trust is a strong predictor of attitude. This result is consistent with previous findings (Ha \& Stoel. 2009; Kim et al., 2009; Palvia, 2009; Suh \& Han, 2002), and imply that the more the sports fans trust the online store and its service, the more likely they have favorable and positive attitude toward using the online store for buying sports merchandise. However, the current study suggests that trust does not have an influence upon online purchase intentions as evidenced by the lack of significance found in the results. Interestingly, this finding contradicts previous studies suggesting that trust-building strategies are essential for the online retailers in order to build long-term relationship with customers (Gefen et al., 2003; Kim et al., 2009; Palvia, 2009; Pavlou, 2003). The results imply that trust might play differential roles for experienced and less experienced online customers. According to Chiu, Lin, Sun, and Hsu (2009), the Internet experience stimulates online purchases, and that online shopping experience tends to influence future online shopping intentions.

Trust, therefore, might play a critical role for those who may not have or have less experience in online transactions due to the potential risks (e.g., customer service, product quality, delivery, security and privacy) (Hur et al., 2008). However, the respondents were not only technologically savvy, but also had experiences purchasing sport products online. As Van der Heijden et al. (2003) suggested, a sport consumer may or may not buy at a trustworthy website that provides a user-friendly environment and reduce feelings of uncertainty. However, the sport consumer will certainly not buy at an untrustworthy website because trust is a threshold variable. Furthermore, it is plausible that the respondents are loyal 
customers to a certain online retailer. Thus, trust might be taken for granted for the experienced customer and might not be considered to be a significant factor in decision making. As Chiu, Hsu, Lai, and Chang (2012) suggested, trust should be taken into consideration in order to build long-term relationships with customers and increase habitual buyers. However, if the website is considered untrustworthy, customers will not utilize the website. Given that gaining customer trust is mainly under the control of online retailers, the online retailers should make great efforts to ensure satisfactory product and service qualities throughout the whole transaction process.

\section{Influence of Attitude}

Attitude did not have a significant influence on online purchase intentions, and provides an important contribution of this study. Although sports fans may develop favorable attitudes toward shopping online, they may not have intentions to buy sports merchandise online. This finding is inconsistent with previous research that suggests a positive impact of attitude on intentions (Ha \& Stoel, 2009; Lin \& Lu, 2000; Palvia, 2009; Van der Heijden, 2003; Yang \& Yoo, 2004).

Several explanations for these results can be offered. First, attitude might be a threshold variable much like perceived ease of use and trust. That is, sport consumers may or may not buy licensed sports merchandise even though they have favorable attitude toward shopping online. Second, sport consumers might visit the online stores to enhance the shopping efficiency by searching for information about the licensed sports merchandise before buying it in the brick-and-mortar stores. This finding supports Levin, Levin, and Weller (2005) who suggested that online preference is greater at the information search stage than the purchase stage. Third, the sample of undergraduate and graduate students might prefer shopping in the traditional retail establishments because they might consider shopping as a fun experience. They might go to conventional stores with their friends and colleagues and enjoy the 
time with them, suggesting they might pursue enjoyment from shopping in these types of establishments.

\section{Conclusion and Future Research}

The purpose of this study was to examine a proposed research model to explain intentions to purchase licensed sport merchandise online. The research model was developed by integrating the TAM and trust and applied to the sport context. Several important conclusions can be drawn from the findings. First, the proposed research model fit the data, while some relationships among the constructs were not consistent as expected. Interestingly, none of hypothesized constructs influenced online purchase intentions. Accordingly, researchers should consider modifying the model by including more paths among the constructs in future research. For example, several researchers have included the influence of trust on perceived usefulness (Gefen, 2004; Ha \& Stoel, 2009) and the influence of perceived ease of use on trust (Gefen et al., 2003), providing some evidence of the significance of the relationships.

Second, this study applied and adapted the TAM that has been widely tested and adopted as a powerful theoretical framework in the information system and e-commerce areas. This study confirmed that the adapted TAM is applicable to the sports context. Perceived ease of use was confirmed to be a strong predictor of perceived usefulness and perceived ease of use to be a strong predictor of attitude. The original TAM postulates that attitude mediates between perceived ease of use and intentions, and between perceived usefulness and intentions. However, the mediating effect of attitude was not found in the current study. The findings imply that perceived ease of use directly influences perceived usefulness, in turn, perceived usefulness influences attitude toward shopping online.

Third, the findings showed that perceived ease of use is a strong predictor of perceived usefulness. The findings suggest that a website should be designed to be user-friendly to enhance its usefulness. Fourth, the results revealed that attitude is influenced by 
perceived usefulness, and fifth, it was found that trust influences attitude. The results suggest that if a website is trustworthy, consumers have favorable and positive attitude toward shopping online. Trust seems to be essential for the online retailers selling licensed sport merchandise. For this reason, online retailers need systematic strategies to build trust toward the website. According to Kim, Ferrin, and Rao (2008), online retailers should pay attention to enhanced privacy and security protection, information quality, their party seals, and reputation to increase trust.

Finally, online purchase intentions were not influenced by perceived ease of use, perceived usefulness, trust, and attitude. The results suggest that even though usefulness and trust toward the website might be considered to be prerequisites for the customers to build a favorable attitude toward online transactions, they may or may not use the website for purchasing licensed sport merchandise. However, the findings also imply that the customers will not use the website if it is not easy to use, useful, and trustworthy. Therefore, online retailers for licensed sport merchandise need sophisticated and systematic plans to make their websites easy to navigate and transact. Sufficient and accurate information about their products should be provided on their websites. As Zhang and Won (2009) suggest, online retailers should establish trust using privacy seal programs such as TRUSTe and BBBOnLine while generating transferred trust for their customers.

Further research is needed to validate the findings because majority of the results of this study are inconsistent with theoretical expectations, and limitations were found. First, there is a possibility of confounding variables that might influence online purchase intentions. The research model could be extended and integrated by including factors that might influence online purchase intentions. For example, several researchers suggested that perceived enjoyment plays a critical role in the extended TAM (Childers et al., 2001; Koufaris, 2002; Teo, Lim, \& Lai, 1999; Venkatesh, 2000). Lin and $\mathrm{Lu}$ (2000) also suggested that information quality influences perceived ease of use and perceived usefulness when using a website. Furthermore, considering the possible differences in online 
purchase behaviors between those who have online shopping experience and those who do not (Chiu et al., 2009), it would be meaningful in the future to include online shopping experience in the research model to test the effect on online purchase intentions of licensed sport merchandise.

Second, the current study was examined using sport merchandise as the object. If the research model is further extended and tested by including sport-specific constructs, it would contribute to understand whether the model can be applied to a sport context in a broader sense. Therefore, it would be meaningful to include sportspecific constructs such as team identification and psychological commitment to the research model in order to explore these relationships.

Third, this study limited the sport products to tangible licensed sport merchandise. Further research is recommended to expand the sport products and examine whether significant difference exists in online purchase intentions between tangible and intangible products. Given that the consumers may have different behavioral patterns when buying tangible and intangible products, the behavioral patterns may be further enhanced when shopping online. 


\section{References}

Ajzen, I., \& Fishbein, M. (1977). Attitude-behavior relations: a theoretical analysis and review of empirical research. Psychological Bulletin, 84(5), 888-918.

Ajzen, I., \& Fishbein, M. (1980). Understanding attitudes and predicting social behavior. Englewood Cliffs, NJ: Prentice Hall.

Ajzen, I., \& Madden, T. J. (1986). Prediction of goal-directed behavior: Attitudes, intentions, and perceived behavioral control. Journal of Experimental Social Psychology, 22(5), 453-474.

Andrew, D. P., Pedersen, P. M., \& McEvoy, C. D. (2011). Research methods and design in sport management. M. Schrag, (Ed.). Champaign IL: Human Kinetics.

Bandura, A. (1982). Self-efficacy mechanism in human agency. American Psychologist, 37(2), 122-147.

Bart, Y., Shankar, V., Sultan, F., \& Urban, G. (2005). Are the drivers and role of online trust the same for all websites and consumers? A large-scale exploratory empirical study. Journal of Marketing, 69(4), 133-152.

Bruner, G., \& Kumar, A. (2005). Explaining consumer acceptance of handheld Internet devices. Journal of Business Research, 58(5), 553-558.

Childers, T. L., Carr, C. L., Peck, J., \& Carson, S. (2001). Hedonic and utilitarian motivations for online retail shopping behavior. Journal of Retailing, 77(4), 511-535.

Chiu, C., Chang, C., Cheng, H., \& Fang, Y. (2009). Determinants of customer repurchase intention in online shopping. Online Information Review, 33(4), 761-784.

Chiu, C., Hsu, M., Lai, H., \& Chang, C. (2012). Re-examining the influence of trust on online repeat purchase intention: The moderating role of habit and its antecedents. Decision Support Systems. 53(4), 835-845.

Chiu, C., Lin, H., Sun, S., \& Hsu, M. (2009). Understanding customers' loyalty intentions towards online shopping: An 
integration of technology acceptance model and fairness theory. Behavior \& Information Technology, 28(4), 347-360.

Da Silva, R. V., \& Alwi, S. F. S. (2008). Online brand attributes and online corporate brand images. European Journal of Marketing, 42(9), 1039-1058.

Davis, F. D. (1986). A technology acceptance model for empirically testing new end-use information systems: Theory and results (Doctoral dissertation, Massachusetts Institute of Technology). Retrieved from http://hdl.handle.net/1721.1/15192

Davis, F. D. (1989). Perceived usefulness, perceived ease of use, and user acceptance of information technology. MIS Quarterly, 13(3), 319-340.

Davis, F. D. (1993). User acceptance of information technology: system characteristics, user perceptions and behavioral impacts. International Journal of Man-Machine Studies, 38(3), 475-487.

Davis, F. D., Bagozzi, R. P., \& Warshaw, P. R. (1989). User acceptance of computer technology: A comparison of two theoretical models. Management Science, 35(8), 982-1003.

Davis, F. D., Bagozzi, R. P., \& Warshaw, P. R. (1992). Extrinsic and intrinsic motivation to use computers in the workplace. Journal of Applied Social Psychology, 22(14), 1111-1132.

Deci, E. L., Koestner, R., \& Ryan, R. M. (1999). A meta-analytic review of experiments examining the effects of extrinsic rewards on intrinsic motivation. Psychological Bulletin, 125(6), 627-668.

Donthu, N., \& Garcia, A. (1999). The Internet shopper. Journal of Advertising Research, 39(3), 52-58.

Everard, A., \& Galletta, D. (2006). How presentation flaws affect perceived site quality, trust, and intention to purchase from an online store. Journal of Management Information Systems, 22(3), 55-95.

Fishbein, M., \& Ajzen, I. (1975). Belief, attitude, intention, and behavior: An introduction to theory and research. Reading. MA: Addison-Wesley Pub. 
Fornell, C., \& Larcker, D. F. (1981). Evaluating structural equation models with unobservable variables and measurement error. Journal of Marketing Research, 18(1), 39-50.

Fournier, S., \& Yao, J. (1997). Reviving brand loyalty: A reconceptualization within the framework of consumer-brand relationships. International Journal of Research in Marketing, 14(5), 451-472.

Gabarro, J. (1978). The development of trust, influence, and expectations. Englewood Cliffs, NJ: Prentice Hall.

Ganesan, S. (1994). Determinants of long-term orientation in buyerseller relationships. Journal of Marketing, 58(2), 1-19.

Gefen, D. (2004). What makes an ERP implementation relationship worthwhile: Linking trust mechanisms and ERP usefulness. Journal of Management Information Systems, 21(1), 263288.

Gefen, D., Karahanna, E., \& Straub, D. W. (2003). Trust and TAM in online shopping: An integrated model. MIS Quarterly, 27(1), 51-90.

Gefen, D., \& Straub, D. W. (2004). Consumer trust in B2c ecommerce and the importance of social presence: experiments in e-products and e-services. Omega, 32(6), 407424.

Ha, H. Y. (2003). Factors influencing consumer perceptions of brand trust online. Journal of Product \& Brand Management, 13(5), 329-342.

Ha, S., \& Stoel, L. (2009). Consumer e-shopping acceptance: Antecedents in a technology acceptance model. Journal of Business Research, 62(5), 565-571.

Hair, J. F., Anderson, R. E., Tatham, R. L., \& Black, W. C. (1998). Multivariate data analysis. Upper Saddle River, NJ: Prentice-Hall.

Hansen, T., Jensen, J. M., \& Solgaard, H. S. (2004). Predicting online grocery buying intention: A comparison of the theory of reasoned action and the theory of planned behavior. International Journal of Information Management, 24(6), 539-550. 
Hur, Y. (2007). Determinants of sport website acceptance: An application and extension of the technology acceptance model (Doctoral dissertation, Washington State University). Retrieved from http://www.dissertations.wsu.edu/Dissertations/Summer2007 /y_hur_072707.pdf

Hur, Y., Ko, Y. J., \& Claussen, C. L. (2011). Acceptance of sports websites: A conceptual model. International Journal of Sports Marketing \& Sponsorship. 12(3), 209-224.

Hur, Y., Ko, Y. J., \& Valacich, J. (2008). Motivation and concerns for online sport consumption. Journal of Sport Management, 21(4), 521-539.

Igbaria, M., Iivari, J., \& Maragahh, H. (1995). Why do individuals use computer technology? A Finnish case study. Information \& Management, 29(5), 227-238.

Im, I., Kim Y., \& Han, H. J. (2008). The effects of perceived risk and technology type on user's acceptance of technologies. Information \& Management, 45(1), 1-9.

Iwasaki, Y., Havitz, M. E. (1998). A path analytic model of relationships between involvement, psychological commitment and loyalty. Journal of Leisure Research, 30(2), 256-280.

Jarvenpaa, S. L., Tractinsky, J., \& Vitale, M. (1999). Consumer trust in an Internet store: A cross-cultural validation. Information Technology and Management, 5(2), 45-71.

Kim, D. J., Ferrin, D. L., \& Rao, H. R. (2008). A trust-based consumer decision-making model in electronic commerce: The role of trust, perceived risk, and their antecedents. Decision Support Systems, 44(2), 544-564.

Kim, H., Kim, T., \& Shin, S. W. (2009). Modeling roles of subjective norms and eTrust in customers' acceptance of airline B2C eCommerce websites. Tourism Management, 30(2), 266-277.

Kline, R. B. (2011). Principles and practice of structural equation modeling. New York, NY: The Guilford Press. 
Koufaris, M. (2002). Applying the technology acceptance model and flow theory to online consumer behavior. Information Systems Research, 13(2), 205-223.

Kwon, H, H., \& Armstrong, K. L. (2006). Impulse purchases of sport team licensed merchandise: What matters? Journal of Sport Management, 20(1), 101-119.

Kwon, H. H., \& Trail, G. (2001). Sport fan motivation: A comparison of American students and international students. Sport Marketing Quarterly, 10(3), 147-155.

Levin, A. M., Levin, I. P., \& Weller, J. A. (2005). A multi-attribute analysis of preferences for online and offline shopping: Differences across products, consumers, and shopping stages. Journal of Electronic Commerce Research, 6(4), 281-290.

Lim, K. H., Sia, C. L., Lee, M. K. O., \& Benbasat, I. (2006). Do I trust you online, and if so, will I buy? An empirical study of two trust-building strategies. Journal of Management Information Systems, 23(2), 233-266.

Lin, J. C., \& Lu, H. (2000). Towards an understanding of the behavioural intention to use a website. International Journal of Information Management, 20(3), 197-208.

Madden, T. J., Ellen, P. S., \& Ajezn, I. (1992). A comparison of the theory of planned behavior and the theory of reasoned action. Personality and Social Psychology Bulletin, 18(1), 3-9.

Mayer, R. C., Davis, J. H., \& Schoorman, F. D. (1995). An integrative model of organizational trust. The Academy of Management Review, 20(3), 709-734.

Moon, J., \& Kim, Y. (2001). Extending the TAM for a World-WideWeb context. Information \& Management, 38(4), 217-230.

Mullin, B. J., Hardy, S., \& Sutton, W. A. (2007). Sport marketing, $3^{\text {rd }}$ ed., Champaign, IL: Human Kinetics.

Nunnally, J. C. (1978). Psychometric theory. New York, NY: McGraw Hill.

Palvia, P. (2009). The role of trust in e-commerce relational exchange: A unified model. Information \& Management, 46(4), 213-220. 
Pavlou, P. A. (2003). Consumer acceptance of electronic commerce: Integrating trust and risk with the technology acceptance model. International Journal of Electronic Commerce, 7(3), 101-134.

Pavlou, P. A., \& Fygenson, M. (2006). Understanding and predicting electronic commerce adoption: An extension of the theory of planned behavior. MIS Quarterly, 30(1), 115-143.

Porter, C. E., \& Donthu, N. (2006). Using the technology acceptance model to explain how attitudes determine Internet usage: The role of perceived access barriers and demographics. Journal of Business Research, 59(9), 999-1007.

Porter, L. W., \& Lawler, E. E. (1968). Managerial attitudes and performance. Homewood, IL: RD Irwin.

Rios, R. E., \& Riquelme, H. E. (2010). Sources of brand equity for online companies. Journal of Research in Interactive Marketing, 4(3), 214-240.

Saadé, R., \& Bahli, B. (2005). The impact of cognitive absorption on perceived usefulness and perceived ease of use in on-line learning: an extension of the technology acceptance model. Information \& Management, 42(2), 317-327.

Schlosser, A. E., White, T. B., \& Lloyd, S. M. (2006). Converting website visitors into buyers: How website investment increases consumer trusting beliefs and online purchase intentions. Journal of Marketing, 70(2), 133-148.

Seo, W. J., \& Green, C. (2008). Development of the motivation scale for sport online consumption. Journal of Sport Management, 22(1), 82-109.

Suh, B., \& Han, I. (2002). Effect of trust on customer acceptance of Internet banking. Electronic Commerce Research and Applications, 1(3-4), 247-263.

Teo, T. S. H., Lim, V. K. G., \& Lai, R. Y. C. (1999). Intrinsic and extrinsic motivation in Internet usage. Omega, 27(1), 25-37.

Teo, T. S. H., \& Liu, J. (2007). Consumer trust in e-commerce in the United States, Singapore, and China. Omega, 35(1), 22-38. 
Tsuji, Y., Bennett, G., \& Leigh, J. H. (2009). Investigating factors affecting brand awareness of virtual advertising. Journal of Sport Management, 23(4), 511-544.

U.S. Census Bureau (2011). http://www.census.gov/econ/estats/

Van der Heijden, H. (2003). Factors influencing the usage of websites: The case of a generic portal in the Netherlands. Information \& Management, 40(6), 541-549.

Van der Heijden, H., Verhagen, T. V., \& Creemers, M. (2003). Understanding online purchase intentions: Contributions from technology and trust perspectives. European Journal of Information Systems, 12(1), 41-48.

Venkatesh, V. (2000). Determinants of perceived ease of use: Integrating control, intrinsic motivation, and emotion into the technology acceptance model. Information Systems Research, 11(4), 342-365.

Venkatesh, V., \& Bala, H. (2008). Technology acceptance model 3 and a research agenda on interventions. Decision Sciences, 39(2), 273-315.

Venkatesh, V., \& Davis, F. D. (2000). A theoretical extension of the technology acceptance model: Four longitudinal field studies. Management Science, 46(2), 186-204.

Vijayasarathy, L. R. (2002). Product characteristics and Internet shopping intentions. Internet Research, 12(5), 411-426.

Wu, J., \& Wang, S. (2005). What drives mobile commerce? An empirical evaluation of the revised technology acceptance model. Information \& Management, 42(5), 719-729.

Yang, H., \& Yoo, Y. (2004). It's all about attitude: revisiting the technology acceptance model. Decision Support Systems, 38(1), 19-31.

Yoon, S. J. (2002). The antecedents and consequences of trust in online-purchase decisions. Journal of Interactive Marketing, 16(2), 47-63.

Zhang, Z., \& Won, D. (2009). The effects of trust in Internet shopping on sport consumers' intentions of purchasing sport product on the Internet. International Journal of Sport Management and Marketing, 6(1), 87-105. 
Zhang, Z., \& Won, D. (2010). Buyer or browser? An analysis of sports fan behavior online. International Journal of Sports Marketing \& Sponsorship, 11(2), 124-139. 